\title{
New Equipment and Software Provided By Virtual Reality Technologies to Visual Designers
}

\author{
Huseyin Baran \\ Faculty of Art Design and Architecture, Visual Communication Design Department, \\ Duzce University, Duzce, Turkey \\ E-mail: huseyinbaran@duzce.edu.tr
}

\begin{abstract}
Technological developments that have made progress in every field of 21 st century, the notion of humanity stepping into computer technologies and the evolution of computer technologies at accelerating speeds in a not too distant history has influenced every technical and technological development that has been experienced which has also diversified its designs by influencing the ways of sharing it with its target audience. Developments in which technological acceleration has taken the lead not only changed the environments and platforms of the designer to meet his / her designs with the target audience, but also offered him the opportunity to create an unlimited number of variations with computer software and hardware technologies. The revolution in the use of light and floor, which began with the appearance of the camera on the stage, has reached to the present day by developing with the possibilities of the internet, moving video, cinema, television, computer technologies, design software. Hardware and software products of virtual reality technologies, which continue to develop day by day, provide new design forms and environments, and provide designers who produce their digital creations by using $\mathrm{X}$ and $\mathrm{Y}$ axes on two-dimensional monitors of computers. Thanks to this Virtual Real environment, where the possibilities of previous software meets new ones, the presentation channels of digital design and produced designs have gained a new dimension and meaning and brought new possibilities of design. In this study, new hardware and software opportunities offered by virtual reality technologies to visual designers are examined.
\end{abstract}

Key Words: Virtual Reality, Visual Design, Technology, Software, Hardware, Digital Painting, Concept Design, 3D Modeling

DOI: $10.7176 / J S T R / 5-12-22$

\section{Sanal Gerçeklik Teknolojilerinin Görsel Tasarımcılara Sunduğu Yeni Donanım Ve Yazılım Olanakları}

\begin{abstract}
Özet
21. Yüzyılın her alanda ilerleme kaydeden teknolojik gelişmeleri, çok uzak sayılmayan bir tarihte insanlığın bilgisayar teknolojilerine adım atması ve bilgisayar teknolojilerinin giderek ivmelenen muhteșem hızlardaki evrimi, sanatın ortaya çıktığı o ilk andan günümüze kadar yaşanan her teknik ve teknolojik gelişme gibi, tasarımcıların çalışma biçimlerini etkilemiş, yanı sıra tasarımlarını hedef kitleleri ile paylaşma yollarını da etkileyerek çeşitlendirmiştir. Teknolojik ivmelenmenin ön ayak olduğu gelişmeler ise, tasarımcının tasarımlarını hedef kitlesiyle buluşturma ortam ve platformlarını değiştirmekle kalmamış, aynı zamanda bilgisayar yazılımları ve donanım teknolojileri ile sınırsız sayıda varyasyona sahip çalışma ortaya koyma olanağını da tasarımcının hizmetine sunmuştur. Fotoğraf makinesinin sahneye çıkması ile başlayan ışık ve zeminin kullanım biçimlerindeki devrim, hareketli video, sinema, televizyon, bilgisayar teknolojileri, donanımlar, tasarım yazılımları, ve internetin sunum olanakları ile gelişerek günümüze kadar ulaşmıştır. Gelişimini günden güne sürdüren sanal gerçeklik teknolojilerinin donanım ve yazılım ürünleri ise yeni tasarlama biçimleri ve ortamlarının doğmasını sağlayarak, dijital yaratılarını bilgisayarların iki boyutlu monitörlerinde $\mathrm{X}$ ve $\mathrm{Y}$ eksenlerini kullanarak
\end{abstract}


üreten tasarımcılara, Z ekseninin derinlik alternatifini kazandırarak, onları, tasarımlarını oluşturabilecekleri gerçeğe daha yakın bir dijital ortama kanalize etmiştir. Önceki yazılımların olanaklarının yenileriyle buluştuğu bu Sanal Gerçek ortam sayesinde, dijital tasarım ve üretilen tasarımların sunum mecraları yeni bir boyut ve anlam kazanarak, tasarıma dair yeni olasılıkları beraberinde getirmiştir. Bu çalışmada, sanal gerçeklik teknolojilerinin görsel tasarımcılara sunduğu yeni donanım ve yazılım olanakları incelenmiştir.

Anahtar Kelimeler: Sanal Gerçeklik, Görsel Tasarım, Teknoloji, Yazılım, Donanım, Dijital Boyama, Konsept Tasarım, 3 Boyutlu Modelleme

\section{Giriş}

İnsanoğlu varolduğu günden bu yana hayallerini yüzeylere aktarmış ve bu görsel aktarma eğiliminde bir tür iletişim kaygısı gütmüştür. Sadece mağara duvarlarındaki çizimler değil, petroglifler gibi Neolitik çağda insanlar tarafından kayalara oyulmuş ve yazı öncesi dönemlere ait sembollerin önemli bir formunu oluşturmuş görsel tasvirlerle, geoglifler gibi, kaya parçalarının dizilimi veya kararmış, yosun tutmuş yüzeylerin kazınması ve benzeri tekniklerle yer yüzeyinde oluşturulmuş büyük boyutlu çizim ve motifler de insanoğlunun geçmişten günümüze bıraktığ 1 görsel miraslardandır.

İnsan, fikir ve düşüncelerini, hayallerini yalnızca aklında yaratmakla kalmaz, aynı zamanda onları bir parçası olduğu topluluğun diğer bireyleriyle de paylaşarak görsel bir kültürel birikimin oluşmasına katkıda bulunur. Topluluk ise bu birikime yeni eklemeler yaparak kültürün gelişmesine, kalıcılığına ve sonraki nesillere aktarılmasına aracı olur. Toplumdan topluma ve dönemden döneme değişiklik gösteren bu kültürel birikim, iletişimin farklı çağlarda farklı yapılara evrilmesini sağlamıştır. İlkel sanatsal çabalarımız, insanoğlunun modern dönemdeki davranışlarına miras kalmış ve günümüzün iletişime dair davranış kalıplarına temel oluşturmuştur.

İnsanoğlunun ilk resimleme çabaları diyebileceğimiz ve bildiğimiz kadarıyla M.Ö. 40.000'lerde başlayan serüvende insan, yaşamının bir parçası olan olayları bazen doğaüstü güçler ve sihir atfettiği resim sanatını kullanarak, yine yaşamını geçirdiği mağara duvarlarına işlemeye başlamıştır. Günümüz teknolojisi ile bilgisayarlarımız vasıtasıyla monitörlerimiz üzerinde oluşturabildiğimiz piksel veya vektörel tabanlı semboller, grafikler ve diğer görsel konseptlerin temelinde, geçmişte duvarlara işlenen bu görsel yaratı kültürünün izleri vardır. O dönemde mağara duvarları vasıtasıyla kurulan görsel iletişim bağı, bugün sosyal medyanın pikseller aracılığıyla dijitalize yüzeylerden yansıyan görüntülerine evrilmiştir.

“Teknoloji” terimine bakıldığında yunancada sanat, zanaat anlamlarına gelen 'tekhne' kelimesinden türediği, zaman içerisinde anlamının değiştiği; bilimsel araştırmalar sonucu elde edilen somut ve yararlı sonuçları ve bunlara ilişkin araç, süreç ve yöntemlerin tümünü ifade eden bir kavram halini aldığı görülür (Vural, 2008: 6).

Teknoloji teknik yönüyle; yani yeni bir şeyleri yeni yöntemler ile ortaya koyma fiili ile her zaman tasarım kavramıla beraber varolmuştur. İnsanoğlu teknolojik bir üretim içerisinde iken, aynı zamanda tasarlıyordur da. İnsanın temel ayırtedici niteliklerinden olan tasarım ise, gelişen teknik ve teknolojik altyapıdan etkilenen yönü ile her daim teknoloji terimi ile birlikte anılagelmiştir. Tasarımcı, bir tasarım süreci içerisine girdiğinde, çoğu zaman dönemin teknolojik olanaklarından faydalanan veya ona katkıda bulunan bir tasarlama eylemini de gerçekleştiriyordur. Milenyum sonrası kendini iyiden iyiye hissettiren dijital çağda bilgisayarlar, tasarımcının, sunulan diğer multimedya donanımlarıyla birlikte, tasarlama eylemini gerçekleştirdiği önemli platformlardan biri haline gelmişlerdir.

Bilgisayarlar, tasarımda mevcut kavramsallaştırma, temsil ve tanımlama araçlarının yerini her zaman için almasa da, onları geniş ölçüde tamamlayan ve güçlendiren bir araç olarak, derin ve dönüştürücü bir etkiye sahiptir (Heskett, 2013: 186).

Görüntü işlemenin analog fotoğraf makineleri ve kameralarla insan hayatına girmesi, basım ve yayın tekniklerinin hızla gelişmesine önayak olmuştur. Dijital çağın getirdiği teknolojik yeniliklerle herkesin kendi fotoğraf ve videolarını çekip dünya ölçeğiyle en uzağındaki kişilerle saniyeler içerisinde paylaşabilmesi ise bu teknolojik gelişimin yeni olanaklarını beraberinde getirmiştir. Bilgisayar teknolojileri ve internetin sunduğu getirilerle birleşen görüntü işlem teknolojileri, sosyal medya kavramını ve bu kavramın varlığını sürdürdüğü dijital ortamı yaratmış, insanların sanal ortamda sosyalleştiği bir 21. Yüzyıl fenomeni ortaya çıkmıştır. Bu ortamın aynı zamanda insan rituel ve alışkanlıklarını öğrenip, sunacağı bilgileri onlara göre şekillendiren yapay zekâyı da içermesi, kullanım kolaylığını artırarak sosyal medyanın daha geniş kitlelerce tercih edilmesini sağlamıştır.

Günümüzün bilimsel, teknolojik ve sosyal gelişmelerinin soyut bir alt ürünü olarak tanımlanabilecek yapay zekâ, halen keşfedilmeyi bekleyen gizemli ve heyecan verici bir alan olarak değerlendirilmektedir. İnsanlığın henüz yeterince bilimsel veri, kaynak ve öngörüye sahip olmadığı bu yeni alan; bireyin 
düşünsel anlamda ortaya koyduğu tutum ve davranış kalıplarını dijital ortama uyarlayabilen yazılım ve donanım bütünleri olarak açıklanabilir. İnsanoğlu, kendi beyninin nasıl çalıştı̆̆ını öğrendikçe, makinelerin de insan beynini taklit edip edemeyeceğine dair bir merak duymuştur. Sanayi ürünleri ve bilgisayar teknolojileri alanlarında insanlığın bilgi ve deneyimleri arttıkça, tecrübelerini bu gelişmeler 1şığında örgütleyerek, kendi doğasına yakın ve düşünebilen dijital yardımcılar kurgulamaya başlamıştır. 1943 yılında Alan Turing'in “makineler düşünebilir mi?” sorusunu gündeme getirmesinden sonra, 1956 yılında Dartmount Konferansı'nda McCarthy "Yapay Zekâ" (Artificial Intelligence: AI) terimini ilk kez kullanmıştır. 1997'de IBM firmasının Deep Blue isimli yapay zekâ sisteminin Gary Kasparov’u satrançta yenmesi bu konuda yapılan çalışmaların ivme kazanmasını sağlamıştır. 2000'li yıllardan itibaren Google başta olmak üzere, IBM, Microsoft, Facebook, Amazon, Apple gibi vizyoner firmalar bu konularda araştırma ve çalışmalarını genişletmişlerdir. Yapay zekâ, günümüzde insanların birbirileri ile daha yakından iletişim kurabilmeleri için yoğun olarak kullanılmaya başlanmıştır. Sosyal medyanın öne çıktığı bu kullanım biçiminde şimdilik "düşük yapay zekâ" olarak adlandırabileceğimiz yeteneklere sahip robotlar gerek insanlar arası iletişimde gerekse onların iletişim yeteneklerini taklit ederek sosyal medyanın çeşitli mecralarında kullanılmaktadır. Instagram'ın veya Facebook'un sosyal çevremizi değerlendirerek yaptığı arkadaş önerileri ile alışveriş alışkanlıklarımızı değerlendirerek sunduğu reklam ürünleri bu konudaki en temel örneklerdir.

Sanal gerçeklik ise, teknolojinin de etkisiyle gelişen, görüntüleme, görüntü işleme, ses ve dokunmaya duyarlı elemanlar gibi birçok bilgisayar içi elektronik donanımlar ya da bilgisayara dışarıdan bağlanan kablolu veya kablosuz çevresel donanımlar sayesinde, adından söz ettirmeye başlamış yeni bir platformdur. Kullanıcıların elektronik gözlük, kulaklık ve dokunmaya duyarlı kontrol cihazlarıyla bağlandıkları ve bulundukları ortamdan yepyeni bir sanal ortama geçerek, gösteri, oyun veya tasarım yazılımlarını deneyimleyebildikleri bu sanal dünya, tasarımcılara da oldukça fazla sayıda sanal yazılım, arayüz ve araç gereç imkânı sunmaktadır.

\section{Sanal Gerçeklik Kavramı ve Teknolojik Gelişimi}

Amerikalı yazar Ray Bradbury, 1950 yılında yayımlanan asıl adı The World the Children Made olan The Veldt adlı öyküsünde zengin bir ailenin çocuklarının oynadıkları, Afrika görüntülerini 3 boyutlu gösterirken, ses, koku gibi duyuları da verebilen bir sistemi konu etmektedir. Çocukların sanal Afrika âlemine olan ilgilerinin endişe verecek boyutlara ulaştığını düşünen ebeveynler bu sanal dünyayı ortadan kaldırma kararlarını çocuklarına ilettikten sonra kaybolurlar. Hikâyenin sonunda sanal dünyadaki Afrika aslanları iki insanı parçalamaktadır. Artık sanal dünyalarında yaşamaya devam eden çocuklar mutludur. Ray Bradbury bu sıra dışı hikâyesiyle sanal gerçeklik kavramının yaratıcısı olarak kabul edilir (Bradbury, 1950)

İnsanoğlunun ihtiyaçları tarihte genellikle gelişimin önünü açan bir olgu olarak yer almıştır. Tekerleğin icadı gibi ilkel diyebileceğimiz tasarımlarımızdan, günümüzün başka gezegenlere seyahat eden araçlarıyla, o gezegenlerin üzerinde ilerleyerek bize anlık fotoğraflar gönderilmesini sağlayan aynı araçların kullandığı tekerleklere uzanan gelişim, tesadüflerin ürünü değildir. Mitlerin başlangıcı, dünyanın bazı bölgelerinde halen devam ettiği üzere, ateş çevresinde nesilden nesile aktarılan hikâyelere dayanır (Wilkinson, P. 2009: 6). Sanal gerçeklik teknolojileri, kullanıcısını alıp götürdüğü kurgulanmış yeni mekânlarla, zamanında imgesel düşüncelerin etkisiyle sözel kökenlere dayandırılarak anlatılan bu mitlerin teknolojik varyasyonları gibidir. Sanal gerçeklik, gerçek dünyanın bilgisayar tarafından yaratılmış üç boyutlu bir ortama aktarılması ve kullanıcının bu ortamda olayları özel aygıtlarla duygusal olarak gerçekmiş gibi algılayabildiği ve aktif olarak denetleyebildiği sistemlerdir (Çavaş vd.. 2004).

Sanal gerçeklik teknolojisi terimi, ilk olarak 1960'ların sonlarında Ivan Sutherland tarafından ortaya atılmış; ilerleyen dönemlerde askeriye, tıp ve oyun gibi sektörlerde büyük ilgi görmüştür. Öğretim alanında da yararlanılmaya başlanan sanal gerçeklik teknolojisi ile dersler daha ilgi çekici hale gelmiş, öğretim daha etkili olmuş ve öğrenciler öğretimde daha aktif rol almışlardır (Dede, 2006).

Sanal Gerçeklik, izleyicinin ya da kullanıcının, oluşturulmuş bir görüntü uzamı içerisine, düzenlenebilir bir zaman yapısı içerisine dâhil olması ve ileri aşamada da onunla etkileşmesi temel ilkesi üzerine kuruludur. Çeşitli girdi ve çıktı teknolojilerinden oluşan güç, hareket, dokunma gibi duyusal etkileri benzeştirerek yeniden üreten aygıtlar, üç boyutlu görüntü ve ses aygitları gibi teknolojik araçlardan oluşan bir ortamdır (Görsel 1). 


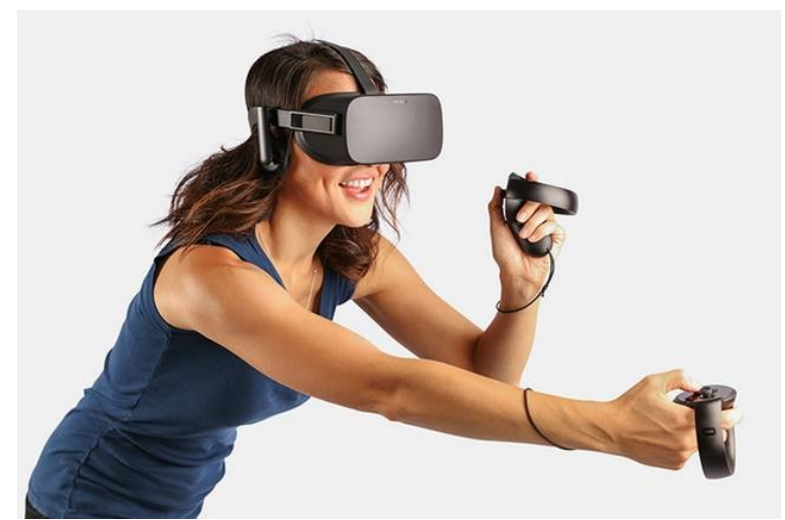

Görsel 1: Sanal gerçeklik gözlüğü ve dokunmatik kontrol donanımlarıyla bir kullanıcı. (https://www.ovrnews.com/wp-content/uploads/2018/07/oculus-rift-fun-650x325.jpg)

Görüntüleme ve görüntü işlem teknolojilerinin uygun elektrik akımı ve elektronik alanındaki gelişmelerle birleşmesi sonucu ortaya çıkan bilgisayar teknolojileri de bu gelişimden nasibini alan ürünlerdir. Bilgisayarlara bağlı monitörler ve bu monitörlere anlık ileti aktaran aygitların bağlı olduğu internet, gelişen dünyada bilginin akışını önemli ölçüde değiştirmiş̧tir. Geleneksel medyanın yerine Yeni Medya kavramını getirerek iletişimde çığır açan bu teknolojiler, son yıllarda tablet bilgisayarlar ve akıllı telefonlarla ceplerimize ve avuç içlerimize kadar gelmiş ve yanında yeni medyanın bilgi aktarım avantajını da kullanıcılarına sunmuştur.

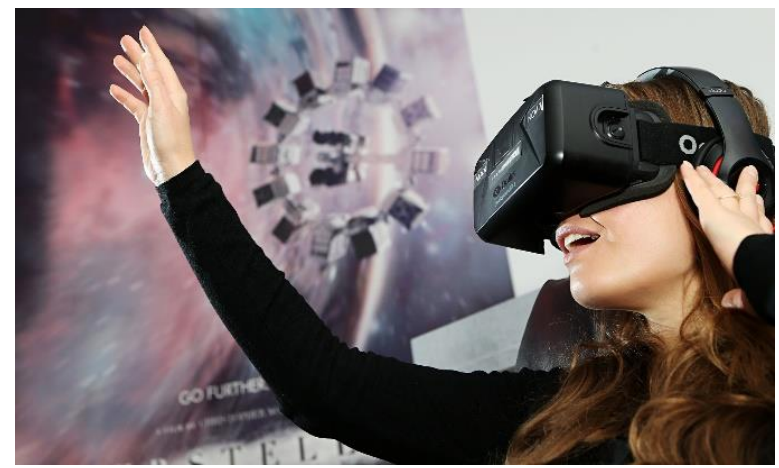

Görsel 2: Sanal gerçeklik donanımı ile bulunduğu ortamdan soyutlanmıș bir kullanıcı. (https://i0.wp.com/gameplaying.info/wp-content/uploads/2016/03/oculus-rift-startshipping.jpg?fit $=1920 \% 2 \mathrm{C} 1152 \&$ ssl $=1$ )

Bilgisayar monitörleri, geleneksel medyadan farklı olarak etkileșim içinde gerçekleșen bir süreçte kullanıcı ile bilgisayar arasındaki iletişimin planlanması ve sürdürülebilmesi için gerekli görsel iletişimi sağlamaktadır. Bu nedenle tüm bilgisayar ekranlarının temel işleyiş mantığı etkileşimlilik üzerine kuruludur (Altunay, 2012: 42). Sanal gerçeklik teknolojileri bu etkileşimi bir üst basamağa taşıyarak bireyi ekranın yarattığı perdeden kurtarmış ve ona mekân içerisinde olma hissini yaşatmayı amaçlamıştır (Görsel 2).

Sanal gerçeklik teknolojilerinin gelişimini tetikleyen en önemli unsurlardan biri, sanatçının yaşamındaki herhangi bir sıradanlığı eserlerine aktardığ 1 ve o sıradanlık içerisinden siyrılmaya çalıştığı anda olduğu gibi, insanoğlunun da kendisine sınırlar belirleyen bu dünyadan sıyrılarak, sıradanlığı yeni deneyimlerle ortadan kaldırma arzusudur. Teknoloji ve makinenin varlık yokluk diyaletiğinde olduğu gibi, sanatçıyı daha çok düşünce ve kavrama yönlendiren bu gibi gelişmeler, Yirminci yüzyılda kendisini tuvalin yerini alan enstelasyonlar, happeningler, performanslar, video sanatı, vücut sanatı ve fluxuslar olarak göstermiş, 21. Yüzyıl yansımasında ise sanal gerçeklik teknolojileri ile kendine yeni bir yol daha oluşturmuştur (Kozlu, 2009: 7).

Her yeni dönem bir öncekinin dönemin yetersizliğinin kabul edilerek, öne geçme arzusunun ağır bastığını düşünürsek, Emprestyonist ressamların fotoğrafin icadından etkilenmelerine benzer bir biçimde, günümüz sanatçı ve tasarımcılarının da yeni teknolojilerden ve bu teknolojilerin sunduğu sanal gerçeklik ve benzeri olanaklardan etkilendikleri düşünülebilir (Ayaydın, 2005: 92). Teknolojinin farklı alanlarında ortaya çıkan yeniliklerin bir araya gelerek oluşturduğu sanal gerçeklik araçları, teknoloji tarihi içerisinde belli süreçlerden geçerek günümüze ulaşabilmiştir. 

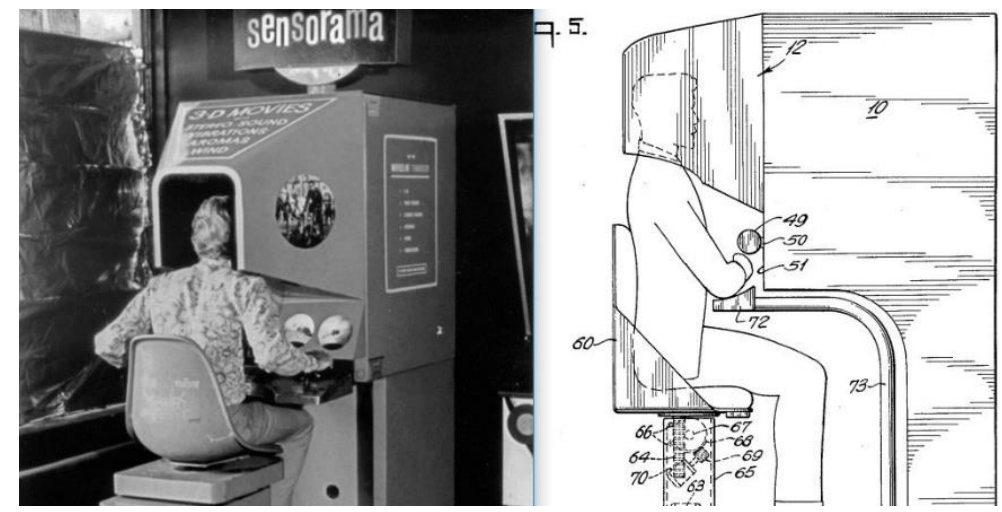

Görsel 3: Sensorama sanal gerçeklik cihazını betimleyen grafik. (https://pbs.twimg.com/media/DFruE00XYAk0vqq.jpg)

S Sanal Gerçeklik donanımları ilk kez 1962 yılında ortaya çıkmıştır. Sensorama isimli cihaz, Morton Heilig tarafından "Geleceğin Sineması” başlıklı 1955 tarihli bir makalede anlatılmıştır (Görsel 3). Geniş açılı bir görüntüde stereoskopik 3D görüntüleri gösterebilen, vücut eğme fonksiyonlu, stereo ses sağlayan ve film sırasında rüzgar ve kokuların izini sürdürebildiğiniz bu cihaz aynı zamanda kulaklık da içeren interaktif bir tiyatro deneyimini andırıyordu (DeMichele, 2016).

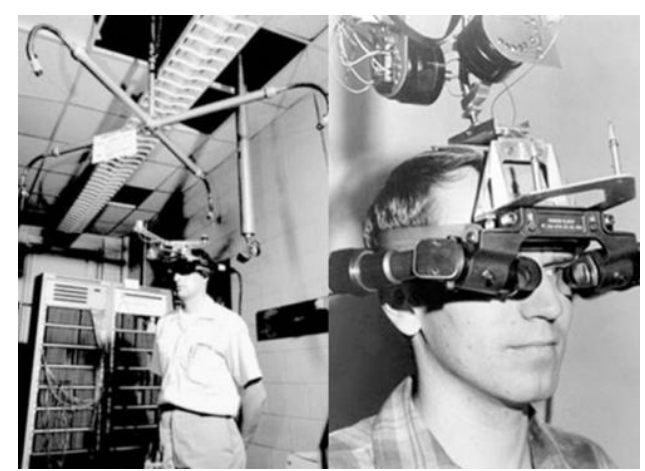

Görsel 4: The Sword of Democles isimli sanal gerçeklik cihazı ve kullanıcısı. (https://miro.medium.com/max/1396/0*ZeHrj5nBBq2mtM8V)

Günümüz sanal gerçeklik kasklarının ilk örneği The Sword of Democles isimli kasktır. Kask anlamında ilk örnek sayılabilecek bu cihaz 1968 yılında Amerikalı bilgisayar mühendisi Ivan Sutherland ve öğrencisi Bob Sproull tarafindan geliştirilmiştir (Görsel 4). Cihaz çok ağır olduğu için tavandan sarkıtılarak kullanılmıştır. İzleyiciye aktardığı görüntüyü binoküler (çift mercekli) ekrana yüklü bir bilgisayar programından sağlamaktaydı. Bu sanal gerçeklik cihazı, sunduğu arayüz ve gerçeklik algısı bakımından günümüz gözlükleriyle karşılaştırıldığında ilkel bir izlenim yaratsa bile modern kasklı ekranların gelişiminde önemli bir kilometre taşı olmuştur (Atakul, 2018).

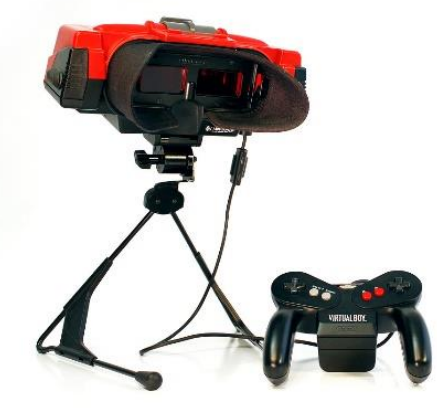

Görsel 5: Virtual Boy sanal gerçeklik kask1. (https://media.pocketgamer.com/artwork/na-jlkg/virtual_boy.jpg) 
Bir diğer sanal gerçeklik donanımı Nintendo firması tarafından 1995 yılında piyasaya sürülen Virtual Boy'dur (Görsel 5). Döneminin görüntü işlem olanaklarının el verdiği ölçüde paralaks derinlik etkisi yaratarak izleyicisini ortamın içerisindeymiş gibi hissettirmeyi amaçlayan bu sanal gerçeklik gözlüğü, müşterilerin beklentilerini karşılamadığ için çıkışından bir yıl sonra piyasadan geri çeklmesine ragmen, bu teknolojinin ilerleyişinde atılmış cesur bir adım olmuştur (Flanagan, 2018).

\section{Yeni Sanal Gerçeklik Donanımları}

Sanal gerçeklik teknolojileri hem bilgisayarların daha hızlı işlem yürütmesine hem de çevresel donanımların daha verimli çalışmasına ihtiyaç duymaktadır. Teknolojik gelişmelerin etkisiyle Sanal Gerçeklik donanımları da zamanla değişime uğramış, günümüzde oldukça modern cihazlar hedef kitlelerinin kullanımına sunulmuştur. Sanal gerçeklik teknolojilerinin hedef kitlesi oldukça geniş bir alanı kapsamakta, çok sayıda meslek için sanal gerçeklik yazılımları gerek eğitim gerekse uygulama amaçlı üretilmektedir. Tıp alanından mühendisliğe, mimarlıktan eğitim bilimlerine bugün birçok alanda sanal gerçeklik teknolojileri özellikle eğitsel amaçlı kullanılmaktadır (Bozan, 2011).

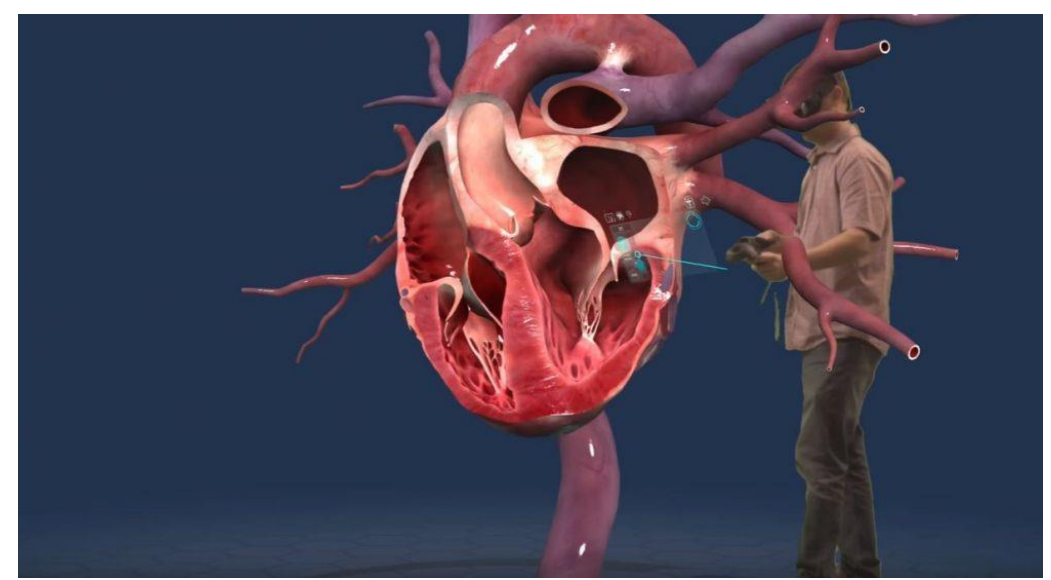

Görsel 6: BodyVR yazılımından bir kare.

(i.pinimg.com/originals/d3/31/fa/d331fa598647235c4d9410164b9be4cc.jpg)

Bu teknolojiler sayesinde bir tıp öğrencisi, eğitimini, gerçeğine çok benzeyen ve sanal elleriyle müdahale edebildiği, tamamiyle sistemlere ya da organlara ayrılabilen sanal insan anatomileri üzerinde alabildiği BodyVR benzeri yazılımları kullanabilmektedir (Görsel 6). Gelişimine her geçen gün devam eden bu teknolojilerin yakın gelecekte sunacağı gerçekçilik hissi ve yeni olanaklar oldukça heyecan uyandırıcı bir hal almıştır.

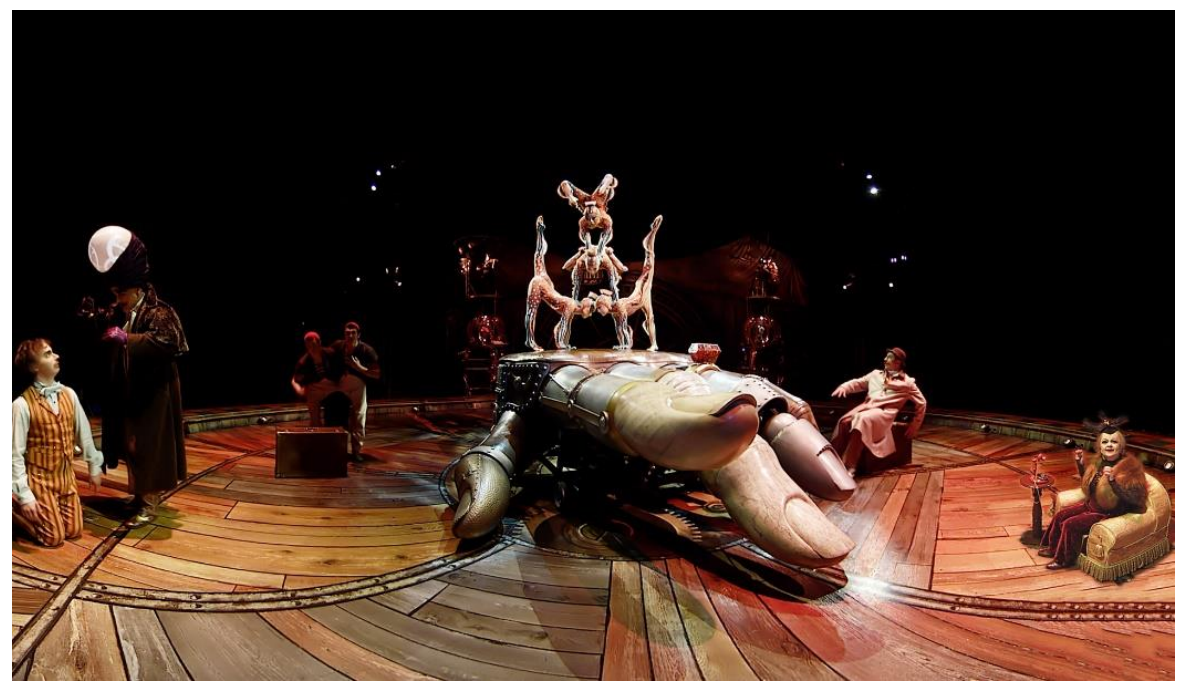

Görsel 7: Circus de Soleil sirk gösterisinden, izleyicisine oradaymış hissi veren sanal gerçek bir kare. (https://roadtovrlive-5ea0.kxcdn.com/wp-content/uploads/2015/06/inside-the-box-of-kurios-gear-vrcirque-du-soleil-experience-2.jpg) 
Aynı zamanda sanal gerçeklik teknolojileri izleyiciyi ekran başından ortamın içerisine çeken yapısıyla, oyun, sinema, tiyatro, sirk ve diğer birçok gösteri ve eğlence temalı yapıtların da izleyiciye ulaşma biçimlerinde ciddi bir evrime sebep olmuştur (Görsel 7). İzleyici, hali hazırda oyunun, filmin ya da gösterinin yalnızca izleyeni değil, aynı zamanda onu yaşayan ve gösterinin devamına varlı̆̆ıyla etki eden merkezdeki bir özne haline gelmiştir.

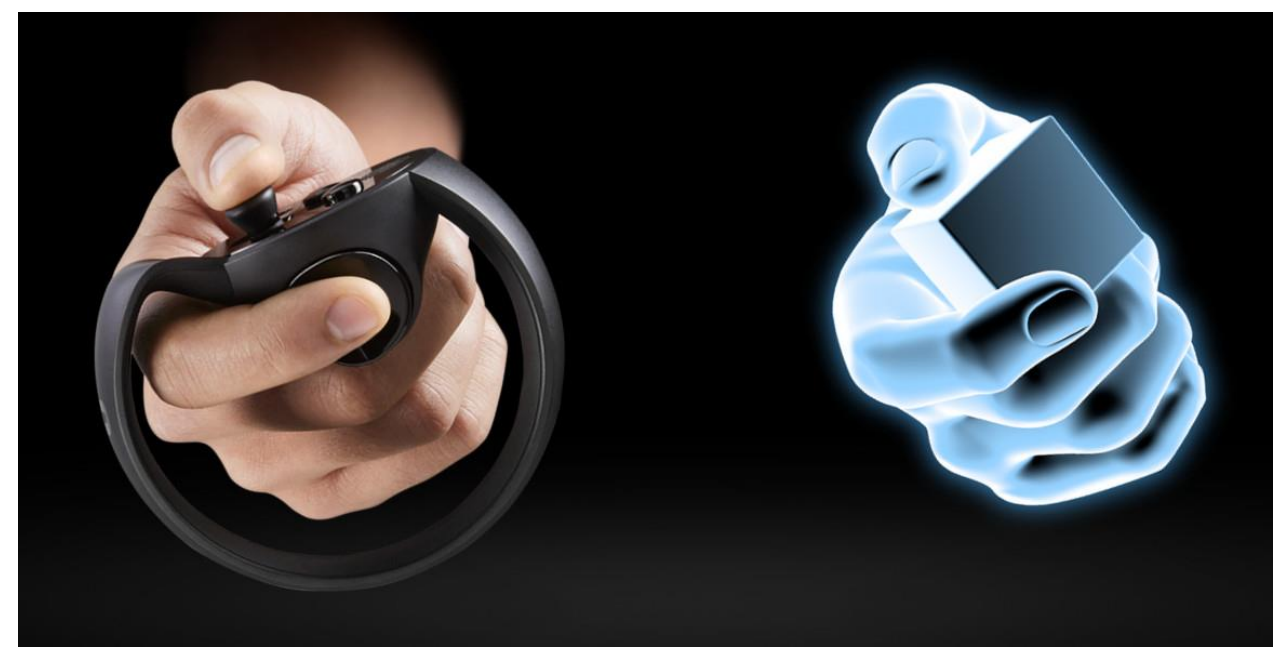

Görsel 8: Sanal Gerçeklik Touch Controller donanımı ve sanal dünyadaki görsel karşıllı̆̆1. (https://static.electronicsweekly.com/wp-content/uploads/2017/01/25110149/oculus-rift-touch.jpg)

Sanal gerçeklik donanımlarının gelişmesi, daha portatif ve rahatsızlık vermeyecek biçimde giyilebilir hale gelmesi, tasarım alanlarıyla dolaylı ya da doğrudan ilintili olan meslek çalışanlarının çalışma yöntem ve tekniklerini etkilemiştir. İnsanoğlunun tasarım serüveni, ham maddeyi ellerine alarak onu belli bir amaç doğrultusunda başkalaştırması ve kendisi için estetik, yararlı veya amacına hizmet edecek yeni bir araç haline getirmesi üzerine kurulmuştur. Sanal gerçeklik donanımları, tasarımcıyı bilgisayarın iki boyutlu ekranlarından üç boyutlu sanal bir mekâna çekerek, dokunmatik control cihazları sayesinde gerçek hayattakine oldukça benzer bir biçimde ellerini kullanma imkânını vermiştir (Görsel 8).

Ellerin ifade gücü sınırsızdır ve herbiri başka bir anlama gelen geniş bir hareket yelpazeleri vardır. Bir ifade aracı olabilecekleri gibi, bir yaratma aracına da dönüşebilirler (Wilkinson, K. 2009: 116). İşte bu doğrultuda sanal gerçeklik ortamının tasarımcıya sunduğu en önemli kazanımlardan biri, ellerini gerçekte olduğuna benzer bir biçimde işe koşabilmesine olanak vermesidir.

\section{Sanal Gerçekliğin Görsel Tasarımcıya Sunduğu Yeni Ortamlar ve Yazılım Olanakları}

Bir önceki teknolojik gelişim olan bilgisayara bağlı monitör, fare ve klavyenin sunduğu tasarım ortamı, yine bilgisayara bağlı olan, ancak çok daha teknolojik bir altyapıya sahip donanımlarla desteklenen sanal gerçeklik aygıtları sayesinde, tasarımcı için yepyeni bir tasarım süreci halini almıştır. Tasarımcı daha önce uyguladığı tasarım süreçlerinin bir çoğunu aynen uygulamakta, tasarım fikrini hayalinde canlandırıp onu bir imge haline getirmekte, kara kalem ve kâğıt ya da grafik tablet ve dijital kalemiyle onu etüt etmekte, tasarısının ilk görselini bu yolla ortaya çıkarmaktadır. Sanal gerçeklik donanımlarının farkı ise tam bu noktada tasarımcıya, eğer uygun yazılımlarla desteklenmişse, gerçek dünyadakine çok benzer araçlara ve fizik kanunlarına sahip olan bir ortam sunarak, normalde ulaşmanın görece zor ve pahalı olduğu araç gereçleri, stüdyoyu veya atölyeyi sanal bir realizmle sunmasıdır.

Sanal gerçeklik ile yaşanan deneyimler derin ve etkilidir. $\mathrm{Bu}$ sayede anlamlı öğrenmeler gerçekleşmektedir (Dede, 2006). Öyle ki sanatçı ya da tasarımcı bu sanal ortamı, dilediğinde yağlıboya tablolarını yapacağ atölye olarak kullanabileceği gibi, ürettiği işleri benzer donanımları kullanan hedef kitlesine sergileyebileceği sanal bir sergi salonu olarak da kullanabilir. Bu olanakları anlamlı kılan yapı ise, donanımlarla uyum içerisinde çalışan yazılımlardır.

Yazılım, bilgisayarın donanımını anlamlı hale getiren, bilgisayarları kişilerin amaçları doğrultusunda kullanmasını sağlayan kod, komut ve programlardır. Günümüzde masaüstü yazılımlarının araç ve olanaklarına sahip sanal gerçeklik tasarım yazılımları da üretilmekte ve bu yazılımlar giderek çoğalmaktadır. Bu yazılımlar sayesinde, sanal gerçeklik teknolojilerini kullanan sanatçı ve tasarımcılar, ürünlerini sanal ortamda üretebilmektedirler (MEB, 2017-2018: 109). 


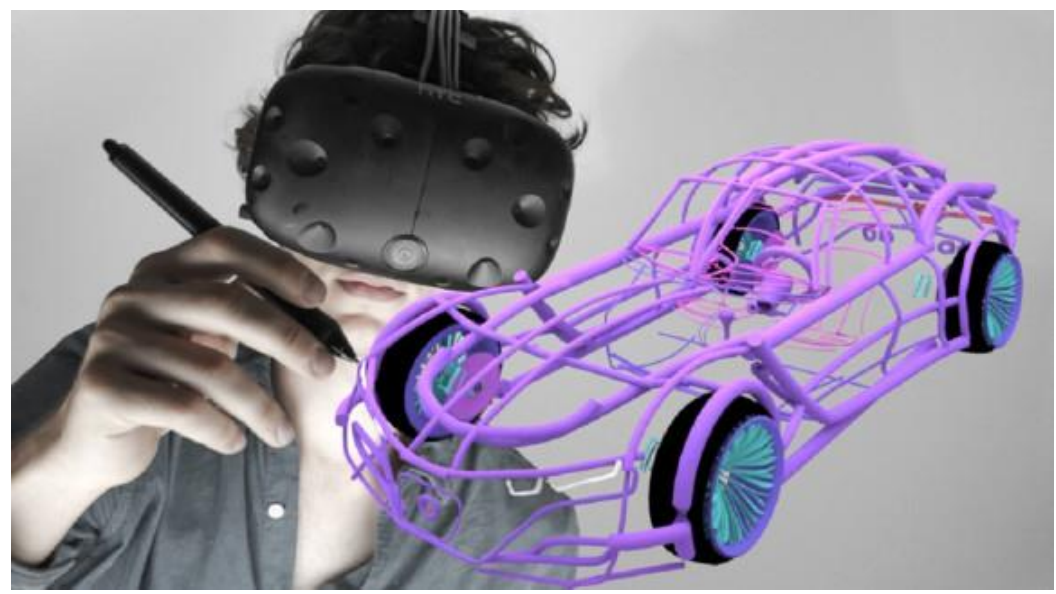

Görsel 9: Gravity Sketch yazılımında tasarım yapan bir kullanıcıyı temsil eden görsel. (https://venturebeat.com/wp-content/uploads/2016/09/gravity-sketch.jpg?fit=578\%2C322\&strip=all)

Gravity Sketch yazılımı bugün birçok tasarımcı tarafindan, tasarıları sanal gerçeklik ortamında yaratmak için kullanılan önemli yazılımlardan biridir (Görsel 9). Bu yazılım, kullanılan gözlük ve dokunmatik kontrol cihazları sayesinde 3D yapılar, karakterler, sahneler veya 3D modeller oluşturmaya olanak verir. En büyük avantajı ise, oluşturulan bu detaylı 3D modelleri, sahneleri ve resimleri sezgisel bir şekilde ortaya çıkarmaya olanak sağlaması ve birçok yardımcı araç barındırmasıdır.

Yeni nesil sanal gerçeklik yazılımları ile bilgisayar ekranında kullanılan yazılımlar arasında bir bağ bulunmaktadır. Sanal ortamdaki yazılımların araç kullanım biçimleri farklı olsa da kullanılan araçları temsil eden ikonlar ve arayüzün yapısı masaüstü yazılımları anımsatmakta, bu durum masaüstü yazılımlara aşina olan tasarımcıların sanal gerçeklik yazılımlarına daha kolay adapte olabilmelerini sağlamaktadır.

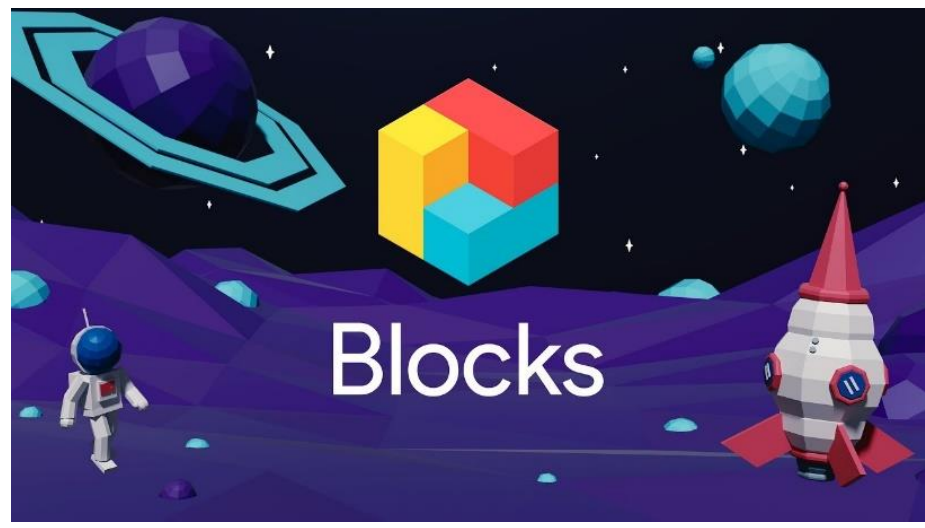

Görsel 10: Blocks yazılımına ait, yazılım içerisinde modellenebilecek yapılara gönderme içeren görsel. (https://i.ytimg.com/vi/1TX81cRqfUU/maxresdefault.jpg)

Bir diğer yazılım olan Blocks, sanal gerçeklikte kolayca 3 boyutlu nesneler oluşturmayı sağlamaktadır (Görsel 10). Altı basit aracı kullanarak tasarımların hayata geçirilebildiği yazılım, volumetrik tasarıma da izin vermekte ve her geçen gün geliştirilen arayüzü sayesinde giderek daha fazla araç ve menüyü kullanıcılarına sunmaktadır. Sanal gerçeklik ortamları gerçek dünyaya uygun olarak tasarlanabileceği gibi istenilen şartlara bağlı olarak gerçeğe aykırı durumlar da bu ortamlara yansitılabilmektedir. (Helsel, 1992).

Sanal gerçeklik ortamları, bu yazılımların yanı sıra Quill VR, Sketchbook VR, Stambol VR, Singularity, Tilt Brush ve theViewer gibi çok çeşitli tasarım alanlarına hitap eden birçok yazılımı tasarımla ilgilenen kullanıcıların hizmetine sunmaktadır. Yazılımların her biri farklı alanlara hitap etmesinin yanı sıra, bazıları birbiri ile etkileşim içerisinde çalışarak tasarımların bir sonraki aşamaya taşınması hususunda yardımcı yazılım olarak da kullanılabilmektedir. Bu yazılımlar aynı zamanda 3Ds Max, Maya ve Octane gibi masaüstü tasarım yazılımlarıyla da etkileşimli bir biçimde çalı̧maya izin vermektedir. Böylelikle sanal gerçeklikte oluşturulan bir tasarım masaüstü yazılımlarında geliştirilebilmekte veya masaüstü yazılımlarıyla oluşturulan bir tasarım sanal gerçeklik ortamındaki yazılımlara aktarılarak bu ortamın yeni olanaklarıly geliştirilebilmektedir. 


\section{Sonuç}

Bir zamanlar kireç taşı, kömür, çamur, kök boyaları, avlanan hayvanların kanları ya da yarasa dışkılarıyla duvarlarda kendisine yer edinen insanoğlunun görsel ürünleri, teknik imkânların gelişmesi ile yağlı boyaya, firçalara, kalemlere ve paletlere evrilmiştir. Yirminci yüzyılın sonlarına doğru gelişimini iyiden iyiye hızlandıran bilgisayar teknolojileri ve dijital platformlar sayesinde sanat ve tasarım, yazılımlar aracılığıyla görselleştirilebilen bir ifade alanı bulmuştur. Yirmibirinci yüzyılın, zamanı daha verimli kullanmayı gerektiren bilgi çağında yazılımlar, sanatçı ve tasarımcıların görsel bir kültür oluşturma ve ürünlerini hedef kitleye ulaştırmada kullandıkları etkili ve vazgeçilmez birer araç haline gelmişlerdir. Bilgisayar teknolojileri ve Sanal gerçeklik alanlarındaki gelişmeler birbirine etki ederek dijital tasarım ve sunum olanaklarını çeşitlendirmiş ve özellikle bu alanda çalışan tasarımcılara yeni olanaklar sağlamıştır. Bu gelişmeler, sanatın dijital olmasının gerekmediği, ancak dijital sanatın gerçekten de bir sanat türü olarak kabul edildiği, dijital teknolojinin ise eğer sanat eseri üretmek amacıyla kullanılırsa ortaya çıkacak sayısız yeni olanaklar sunduğu bir dünyanın kapıları aralamıştır. Sanal gerçeklik teknolojileri ve sunduğu yeni tasarım olanakları, yeniliğe açılan bu kapılarından yalnızca biridir. Gelişsim ise, insanoğlunun tasarım bilinci ile hareket ettiği her alanda olduğu gibi, Sanal Gerçeklik teknolojileri alanında da daha iyiye doğru evrilmeye devam etmektedir. Sanatçı ve tasarımcıların görsel tasarım yetenekleri, sanal gerçeklik teknolojilerinin sunduğu üç boyutlu uzamla birleşerek, gerçeklik hissini her geçen gün biraz daha arttıran sanal bir gerçekliğin yeni sunum ortamlarını yaratmıştır. Bu yeni ortamlar sanatçı ve tasarımcının hem yeni tuvali haline gelmiş, hem de tüm bireyleri sanatın mekânına dijital anlamda dâhil etmiştir. Bir zamanlar mağara duvarlarına büyü ritüelleri, bereketli avlar, sağlık ve şifa amacıyla aktarılan görsel tasarım sembolleri, dijital dünyanın sanal duvarlarında her geçen gün gelişen bir realizmle kendini göstererek günümüz insanının yeni sembolizmini yaratmıştır.

\section{Kaynakça}

Altunay, A. (2012). Geleneksel Medyadan Yeni Medyaya: Görüntü Yüzeyi. Selçuk Üniversitesi Sosyal Bilimler Enstitüsü Dergisi, 42.

Bozan, (2011), “Dijital Teknolojinin Plastik Sanatlara Sağladığı Olanaklar”, Yüksek Lisans, Kocaeli Üniversitesi Sosyal Bilimler Enstitüsü, Kocaeli.

Çavaş, B., Huyugüzel, P., Can, B. 2004, Eğitimde sanal gerçeklik. The Turkish Online Journal of Educational Technology [Electronic Journal], 3: 110- 116,

Çavaş, B., Huyugüzel P ve Can B. (2004) Eğitim de Sanal Gerçeklik Uygulamaları.

Dede, C. 1995. The evolution of constructivist learning environments: Immersion in distributed, virtual worlds. Educational Technology, 35: 46-52.

Dede, C. 2006. Introduction to virtual reality in education. Themes in Science and Technology Education, 1: 7-9.

Helsel, S. 1992. Virtual reality and education. Educational Technology, 32: 38- 42.

Heskett, J. (2013, Ağustos). Tasarım (E.Uzun, Çev.). Ankara: Kültür Kitaplığı, 186.

Kozlu, D. (2009, Mart). Teknolojik Gelişmelerin Toplum ve Sanata Yansımaları. Süleyman Demirel Üniversitesi, Güzel Sanatlar Hakemli Dergisi, 7.

MOİR, Lance. (2001), “What Do We Mean By Corporate Social Responsibility?”, Corporate Governence, 1(2), MCB University Press

Vural, B., Sabuncuoğlu A. (2008, Mart). Bilgi İletişim Teknolojileri ve Ütopyan Bakış Açısı. Selçuk İletişim, 6. 
Wilkinson, K. (2009). Semboller ve İşaretler. İstanbul: Alfa Yayınları, 116.

Wilkinson, P. (2009). Efsaneler ve Mitler. İstanbul: Alfa Yayınları, 6.

\section{Elektronik Kaynaklar}

Atakul, B. Sanal Gerçeklik Nedir? Kullanım Alanları Nelerdir?. (Mart 2018). Erișim: 19.05.2018,

http://www.teknolo.com/sanal-gerceklik-nedir/

DeMichele, T. The Sensorama Was the First VR Device. (Ocak 2016). Erişim: 18.05.2018, http://factmyth.com/factoids/the-sensorama-was-the-first-vr-device/

Dergi Park.(2007) (t.y.) Erişim Tarihi: 18 Mayıs 2018 http://dergipark.gov.tr/ataunigsfd/issue/2600/33460

Flanagan, G. The incredible story of the 'Virtual Boy' — Nintendo's VR headset from 1995 that failed spectacularly. (Mart 2018). Erişim: 16.05.2018,

http://www.businessinsider.com/nintendo-virtual-boy-reality-3d-video-games-super-mario$\underline{2018-3}$

Körotonomedya, İnternette Sanat Mümkün mü?. (2012, Haziran). Erişim: 06.04.2018 http://www.korotonomedya.net/kor/index.php?id=6,7,0,0,1,0

Techinside (18 Aralık 2017), Erişim: 16 Aralık 2018

https://www.techinside.com/sanal-gerceklik-sosyal-medyanin-gelecegi/ 